\title{
CD11c-Positive Dendritic Cells in Triple-negative Breast Cancer
}

\author{
HEEJAE LEE ${ }^{1,2}$, HEE JIN LEE ${ }^{1}$, IN HYE SONG ${ }^{3}$, WON SEON BANG ${ }^{1,2}$, \\ SUN-HEE HEO ${ }^{1,2}$, GYUNGYUB GONG $^{1}$ and IN AH PARK ${ }^{1}$ \\ ${ }^{1}$ Department of Pathology, and ${ }^{2}$ Asan Center for Cancer Genome Discovery - Asan Institute for Life Sciences, \\ University of Ulsan College of Medicine, Asan Medical Center, Seoul, Republic of Korea; \\ ${ }^{3}$ Department of Hospital Pathology, Seoul St. Mary Hospital, College of Medicine, \\ The Catholic University of Korea, Seoul, Republic of Korea
}

\begin{abstract}
Background: Tumor-infiltrating lymphocytes (TILs) and tertiary lymphoid structures (TLSs) are prognostic markers in triple-negative breast cancer (TNBC). Our study analyzed the relationship between cluster of differentiation (CD)11c-positive dendritic cells (DCs) and TILs and TLSs to elucidate mechanisms of TIL influx. Materials and Methods: Immunohistochemical staining for CD4, CD8, and CD11c in tissue microarrays from 681 patients with TNBC was performed. The proportions of TILs and TLSs were reviewed. Two additional TNBC gene expression datasets were used. Results: CD11c expression showed a significantly positive correlation with the level of TILs and the number of $\mathrm{CD}^{+}$and $C D 8^{+} T$-cells, as well as an abundance of TLSS. CDI1C gene expression was also significantly correlated with expression of CD4, CD8, and genes related to TLSs in both datasets. Conclusion: We demonstrated a strong correlation of CD11c expression, which represents DCs, with TILs and TLSs in TNBC. Further investigation is warranted to identify therapeutic modalities that facilitate recruitment and activation of DCs.
\end{abstract}

Although triple-negative breast cancer (TNBC) shows aggressive clinical features, patients with higher levels of tumor-infiltrating lymphocytes (TILs) and tertiary lymphoid

This article is freely accessible online.

Correspondence to: In Ah Park, Department of Pathology, University of Ulsan College of Medicine, Asan Medical Center, 88 Olympic-ro 43-gil, Songpa-gu, Seoul 138-736, Republic of Korea. Tel: +82 230100141, Fax: +82 24727898, e-mail: natz821@naver.com; Gyungyub Gong, Department of Pathology, University of Ulsan College of Medicine, Asan Medical Center, 88 Olympic-ro 43-gil, Songpa-gu, Seoul 138-736, Republic of Korea. Tel: +82 230104554, Fax: +82 24727898, e-mail: gygong@amc.seoul.kr

Key Words: Breast cancer, dendritic cell, CD11c, tumor-infiltrating lymphocyte. structures (TLSs) in the tumor microenvironment have better clinical outcomes $(1,2)$. In order to explore mechanisms of TIL influx in the TNBC microenvironment, we previously analyzed the relationship between the expression of endoplasmic reticulum stress (ERS) molecules protein kinase R-like endoplasmic reticulum kinase (PERK), phosphorylated eukaryotic initiation factor $2 \alpha$ (p-eIF $2 \alpha$ ), and X-box binding protein (XBP1), and danger-associated molecular patterns (DAMPs), including high mobility group B1 and N1 (HMGB1 and HMGN1) proteins in tumor cells, and the level of TILs in patients with TNBC. Higher expression of ERS molecules in cancer cells was associated with higher cytoplasmic expression of HMGB1 and HMGN1, which are nuclear proteins and known to be released in the context of ERS and higher TIL levels in TNBC $(3,4)$. We also confirmed that HMGB1/HMGN1 were released into the extracellular space from several TNBC cell lines upon pharmacological ERS, which suggests that ERS triggers the release of HMG proteins following TIL influx in TNBC (3).

Tumor cells, dendritic cells (DCs; representative antigenpresenting cells in adaptive immunity), and cytotoxic T-cells are organizationally coordinated during antitumor immune responses. DAMPs, including HMGB1, were originally found to be released by damaged tissue but have also been discovered to be released by different tumor types (5). It is suggested that HMGB1 secretion also has roles in cancer (5, 6). HMGB 1 binds to toll-like receptor 4 (TLR4) on DCs, which exerts an important role in subsequent T-cell activation $(7,8)$.

The association between DAMPs and TILs, however, has not been thoroughly investigated clinically. Murakami et al. reported that high expression of major histocompatibility complex class I polypeptide-related sequence $\mathrm{A}$ and $\mathrm{B}$ (MICA/B), a DAMP component that is specifically induced by chemotherapy, and irradiation, was associated with a low ratio of regulatory T-cell (Tregs) to TILs in patients with pancreatic cancer who underwent neoadjuvant chemoradiotherapy (9). The control group, who did not receive neoadjuvant therapy, 
showed no such significant association (9). In colon cancer, HMGB1 expression in both the nucleus and cytoplasm was reported to be inversely associated with the amount of both cluster of differentiation $(\mathrm{CD}) 3^{+}$and $\mathrm{CD}^{+} 5 \mathrm{RO}^{+}$T-cells infiltrating the tumor stroma (10). In lung adenocarcinoma, high densities of infiltrating DCs have been reported to be associated with cytoplasmic HMGB1 expression and with greater numbers of TILs (11).

In order to determine the relationship between DCs and Tcells, our study analyzed CD11c, CD8 and CD4 expression and the level of TILs and presence of TLSs in surgical specimens of TNBC without previous systemic therapy. The expression of genes related to DCs, T-cells, and TLSs was investigated using The Cancer Genome Analysis (TCGA) data (http://www.gdac.broadinstitue.org), as well as biopsy specimens from patients with TNBC who received neoadjuvant chemotherapy.

\section{Materials and Methods}

Patients and specimens. We analyzed tissue microarrays from 681 previously described preoperative chemotherapy-and radiotherapynaïve patients with TNBC who underwent surgery for primary breast cancer between 2004 and 2010 at the Asan Medical Center, Seoul, Korea (12). All patients underwent adjuvant systemic treatment, and 471 patients $(69.2 \%)$ without lymph node metastasis were treated with four cycles of adjuvant anthracycline and cyclophosphamide (AC) (adriamycin $60 \quad \mathrm{mg} / \mathrm{m}^{2}$ and cyclophosphamide $600 \mathrm{mg} / \mathrm{m}^{2}$ ). The remaining 210 patients with lymph node metastasis were treated with four cycles of AC followed by either four cycles of paclitaxel $\left(175 \mathrm{mg} / \mathrm{m}^{2}\right)$ or four cycles of docetaxel $\left(75 \mathrm{mg} / \mathrm{m}^{2}\right)$. Exemption from informed consent, after deidentification of information, was approved by the Institutional Review Board of the Asan Medical Center. This study was performed in accordance with the Declaration of Helsinki.

The hematoxylin and eosin-stained slides were reviewed by two pathologists (H.J.L. and G.G.). The histological grade of breast cancer was evaluated according to the modified Bloom-Richardson grading system (13). The slides were evaluated for stromal TIL levels using full sections in $10 \%$ increments (if TIL was less than $10 \%$, one out of 0,1 , or $5 \%$ was chosen), and the proportion of TLSs in the adjacent area of the invasive tumor was graded as: None: No TLS formation in the area adjacent to the tumor; little: TLSs occupying an area of less than $10 \%$ of the circumference of the tumor; moderate: $10 \%$ to $50 \%$ coverage; and abundant: greater than $50 \%$ coverage $(2,14)$.

Immunohistochemical analysis. Formalin-fixed, paraffin-embedded tissue microarray sections were stained with an automatic immunohistochemical staining device (Benchmark XT; Ventana Medical Systems, Tucson, AZ, USA). Antibodies for CD11c (1:1000; Abcam, Cambridge, UK), CD4 (1:4; Ventana Medical System), and CD8 (1.200; Dako, Glostrup, Denmark) were used. CD11c-immunostained slides were scanned using a Vectra 3.0 microscope system (PerkinElmer, Waltham, MA, USA). The entire slide $(\times 4)$ was scanned first and then we selected and took images $(\times 20)$ from tissue microarray cores. Integrated optical density was obtained from the sum of multiplying the average intensity of 3,3'- diaminobenzidine (DAB) staining and the number of pixels of DAB-stained areas.

The immunostained tissue microarray slides for CD4 and CD8 were scanned using a digital microscope scanner (Pannoramic 250 FLASH; 3DHISTECH Ltd., Budapest, Hungary) as previously described (12). The number of $\mathrm{CD}^{+}$and $\mathrm{CD}^{+}$cells was determined using the NuclearQuant module of the Pannoramic Viewer 1.15.2 (3DHISTECH Ltd).

Gene expression analysis. Two sets of TNBC gene expression data were used to analyze the relationship of CD11c positivity with Tcells and TLSs. The first set consisted of 55 TNBC biopsy cases prior to neoadjuvant chemotherapy (15). Total RNA (100 ng) extracted from formalin-fixed paraffin-embedded biopsy specimens was assayed on an nCounter Digital Analyzer with nCounter GX Human Immunology V2 kit (NanoString, Seattle, WA, USA) (16). Data were normalized by scaling with the geometric mean of builtin control gene probes for each sample and were $\log 2$-transformed. The second set consisted of 189 TNBC cases from TCGA invasive breast cancer data downloaded from the Broad GDAC Firehose website (https://gdac.broadinstitute.org). the mRNA expression (RNA seqV2 RSEM) of eight immune-related genes was analyzed: CD4, CD8A, CD8B, C-C motif chemokine ligand 21 (CCL21), C$\mathrm{X}-\mathrm{C}$ motif chemokine ligand 12 (CXCL12), CXCL13, lymphotoxin beta $(L T B)$, and CD11c (17).

Statistical analyses. All statistical analyses were carried out using SPSS version 20 (IBM Corp., Armonk, NY, USA). Spearman correlation, chi-square test, linear by linear test, log-rank test, and Cox proportional hazards regression model were used, as appropriate. All tests were two-sided with a $95 \%$ significance level.

\section{Results}

T-Cell and CD11c distribution. On microscopic examination, CD11c positivity was predominantly observed in areas with larger numbers of TILs and TLSs (Figure 1). Counting DCs is difficult due to their extended dendrites, therefore the integrated optical density for CD11c positivity was used to quantify DCs in the TNBC microenvironment (18). The distributions of $\mathrm{CD}^{+}$and $\mathrm{CD}^{+}$T-cells and $\mathrm{CD} 11 \mathrm{c}$ integrated optical density were skewed to the left (Figure 2). The median $\mathrm{CD}^{+}$and $\mathrm{CD}^{+}$T-cell counts per tissue microarray core were 1171 (range=6-7,161) and 335 (range $=1-4,443$ ), respectively. The median integrated optical density for CD11c positivity was 12,703 (range=12.7309,903.6).

Comparison of clinicopathological variables according to CDI1c expression in patients with TNBC. The integrated optical density of $\mathrm{CD} 11 \mathrm{c}$ positivity was significantly positively correlated with TIL levels (Spearman's rho $=0.483$, $p<0.001)$ and number of $\mathrm{CD}^{+}(\mathrm{rho}=0.591, p<0.001)$ and $\mathrm{CD}^{+} \mathrm{T}$-cells (rho $=0.515, p<0.001$, Figure 3 ). In order to analyze clinicopathological correlation, tumors were divided into two groups based on the median integrated optical density for CD11c positivity. Tumors with higher CD11c 

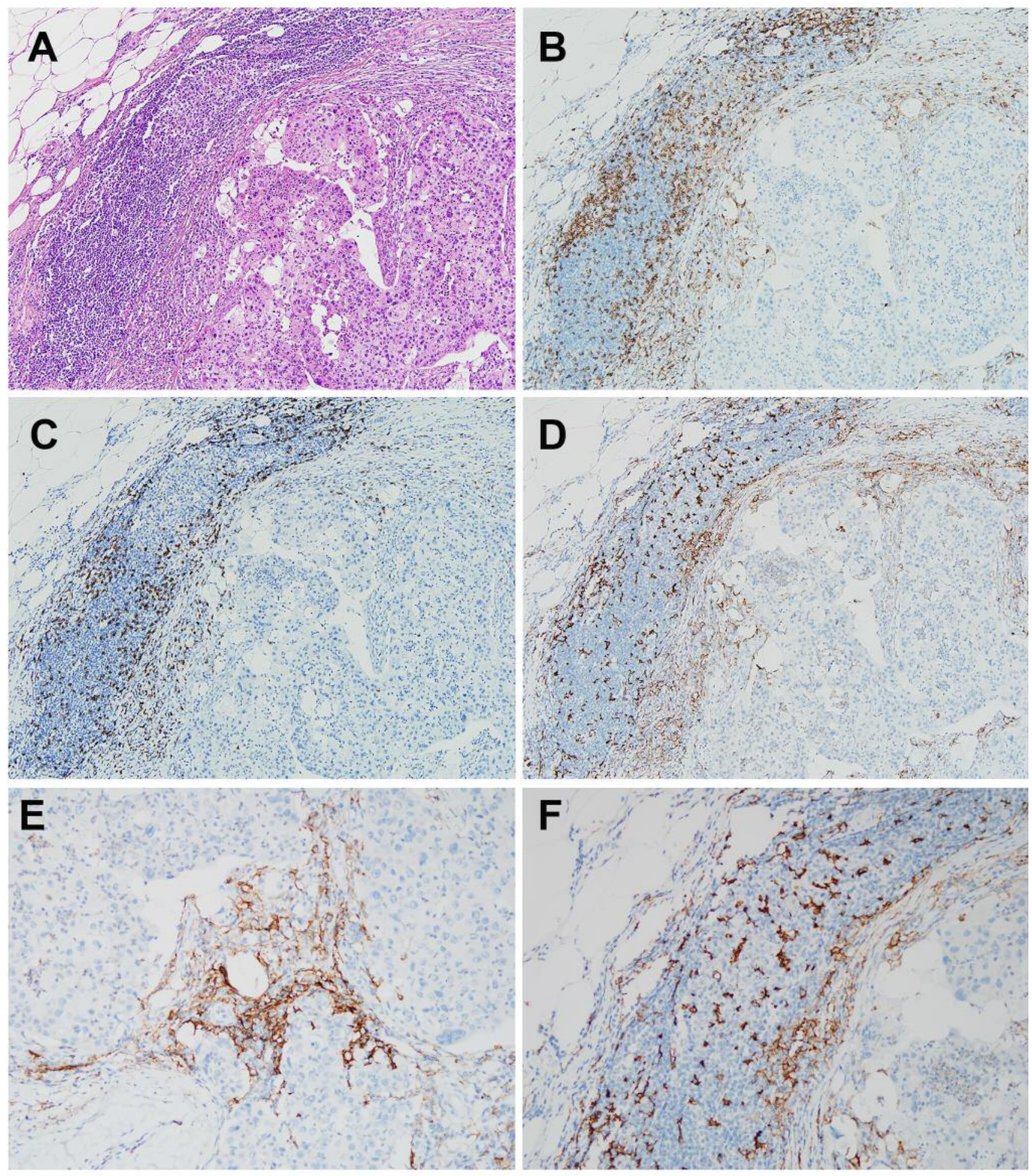

Figure 1. Histological features and distribution of immune cells of triple-negative breast cancer with abundant tumor-infiltrating lymphocytes (TILs) and tertiary lymphoid structure (TLS) formation. A: High-grade tumor cells with TILs and TLS (upper left) are shown (H\&E-stained, $\times 100)$. B-D: Distribution of cluster of differentiation $(C D) 4^{+} T$-cells $(B), C D 8^{+} T$-cells $(C)$ and dendritic cells $(D)$ throughout TILs and TLS are highlighted by immunohistochemistry $(\times 100)$. E, F: Dendritic cells showing CDI1c expression are predominantly located in areas with large numbers of TILs $(E$, $\times 200)$ and $T L S(F, \times 200)$. 

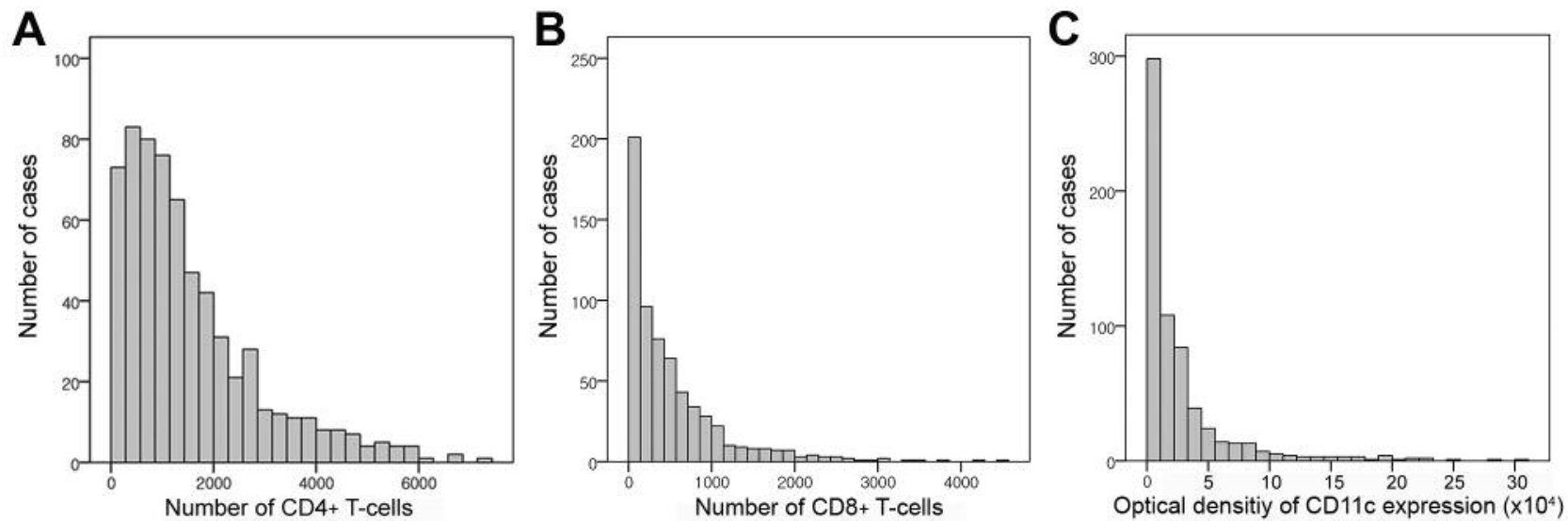

Figure 2. Distribution of cluster of differentiation $(C D) 4^{+}$and $C D 8^{+} T$-cells and CD11c positivity. The number of $C D 4^{+} T$-cells $(A)$ and $C D 8^{+}$ $T$-cells $(B)$ in tissue microarray cores were automatically counted and are shown in a histogram. The mean number of CD4 ${ }^{+} T$-cells was larger than that of $C D 8^{+} T$-cells, and both their distributions are left-skewed. The optical density of CD11c expression (C) measured instead of counting dendritic cells suggests that the distribution of dendritic cells is also skewed to the left.
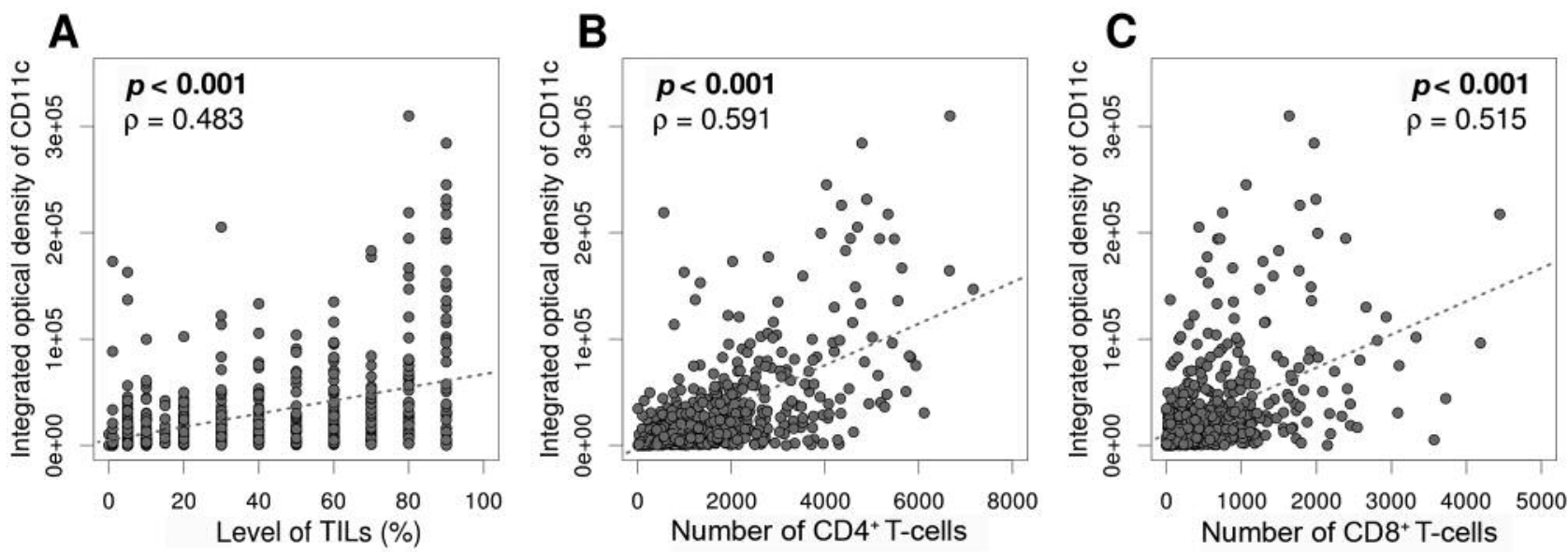

Figure 3. Correlation between cluster of differentiation (CD)11c expression and the abundance of tumor-infiltrating lymphocytes (TILs) (A) and $\mathrm{CD}^{+}{ }^{(B)}$ and $C D 8^{+}(C)$ T-cells. Integrated optical density of CD11c positivity was significantly positively correlated with the abundance of TILs, the number of $\mathrm{CD}^{+}$T-cells, and that of $C D 8^{+} T$-cells.

expression had significantly higher histological grades $(p=0.011)$ and more abundant surrounding TLSs $(p<0.001$, Table I). Pathological T stage and presence of lymph node metastasis and lymphovascular invasion did not vary by CD11c expression level.

Prognostic significance of CD11c expression in patients with $T N B C$. Chemotherapy regimens and TNBC prognosis differed according to lymph node metastasis status; survival analyses were, therefore, performed on patients according to lymph node metastasis. Among patients without lymph node metastasis, there was no difference in survival between those with high or low CD11c expression (recurrence-free survival, $p=0.824$; overall survival, $p=0.383$, Figure 4 ). On the other hand, in the group with lymph node metastasis, high CD11c expression showed a trend for being associated with better recurrence-free survival $(p=0.284)$ and significantly better overall survival $(p=0.047)$ compared to low CD11c expression. However, in multivariate analysis (including pathological T stage, lymphovascular invasion, TIL level and CD11c expression), CD11c expression was not independently associated with better overall survival in patients with lymph node metastasis [pathologicaI $\mathrm{T}$ stage, hazard ratio $(\mathrm{HR})=1.147$, 95\% confidence interval $(\mathrm{CI})=0.720-1.827$, 
Table I. Clinicopathological correlation of CD11c positivity in consecutive triple-negative breast cancer cohorts.

\begin{tabular}{lrrr}
\hline & \multicolumn{3}{c}{ CD11c positivity, n (\%) } \\
\cline { 2 - 4 } Characteristic & Low & High & $p$-Value \\
\hline Histological grade & & & 0.011 \\
2 & $94(28.0)$ & $64(19.5)$ & \\
3 & $242(72.0)$ & $265(80.5)$ & \\
Pathologic T-stage & & & 0.891 \\
1 & $147(43.8)$ & $143(43.5)$ & \\
2 & $174(51.8)$ & $176(53.5)$ & \\
3 & $15(4.5)$ & $9(2.7)$ & \\
4 & $0(0.0)$ & $1(0.3)$ & \\
Lymph node metastasis & & & 0.855 \\
Negative & $256(76.2)$ & $253(76.9)$ & \\
Positive & $80(23.8)$ & $76(23.1)$ & \\
Lymphovascular invasion & & & 0.866 \\
Negative & $232(69.0)$ & $230(69.9)$ & \\
Positive & $104(31.0)$ & $99(30.1)$ & \\
TLS adjacent to the invasive area & & & $<0.001$ \\
None & $43(12.8)$ & $11(3.3)$ & \\
Mild & $68(20.2)$ & $39(11.9)$ & \\
Moderate & $135(40.2)$ & $111(33.7)$ & \\
Severe & $90(26.8)$ & $168(51.1)$ & \\
\hline
\end{tabular}

TLS, Tertiary lymphoid structure.

$p=0.565 ;$ lymphovascular invasion, $\mathrm{HR}=2.006,95 \%$ $\mathrm{CI}=1.080-3.726, p=0.028$; TIL, HR=0.978, 95\% CI=0.965$0.991, p=0.001$; CD11c, $\mathrm{HR}=1.0,95 \% \mathrm{CI}=1.0-1.0, p=0.394]$.

Gene expression analysis with two different TNBC cohorts. In order to confirm the close relationship of CD11c with Tcells and TLSs, we analyzed the associated gene expression in two different TNBC cohorts. The first set consisted of 55 TNBC cases with NanoString-based gene expression data, covering genes associated with TLSs (CXCL12 and CXCL13) $(15,19)$. The second set consisted of RNA sequencing data of 189 TNBC cases from TCGA breast cancer data, which included genes associated with TLSs (CCL21, CXCL12, CXCL13, and LTB). In the first set, CD11c gene expression was positively associated with $C D 4$, $C D 8 A, C D 8 B, C X C L 12$, and $C X C L 13$ expression (rho $>0.5$, $p<0.001$, Table II). Likewise, $C D 11 C$ gene expression was also positively correlated with $C D 4, C D 8$, and other genes related to TLSs, including $L T B$ in the second dataset (rho $>0.4, p<0.001$, Table III).

\section{Discussion}

CD11c, a member of the integrin $\beta 2$ adhesion molecule family, is highly expressed in monocytic and myeloid DCs, which are representative antigen-presenting cells (20). Antigen-presenting
Table II. Correlation between genes associated with T-cells and tertiary lymphoid structures and CD11C from patients with triple-negative breast cancer using NanoString-based gene expression data $(n=55)$.

\begin{tabular}{lcrrrrr}
\hline & & CD8A & CD8B & CXCL12 & CXCL13 & \multicolumn{1}{c}{ CD11C } \\
\hline \multirow{2}{*}{ CD4 } & Rho & 0.806 & 0.695 & 0.534 & 0.715 & 0.804 \\
& $p$-Value & $<0.001$ & $<0.001$ & $<0.001$ & $<0.001$ & $<0.001$ \\
CD8A & Rho & & 0.855 & 0.443 & 0.749 & 0.566 \\
& $p$-Value & & $<0.001$ & 0.001 & $<0.001$ & $<0.001$ \\
CD8B & Rho & & & 0.334 & 0.603 & 0.528 \\
& $p$-Value & & 0.013 & $<0.001$ & $<0.001$ \\
CXCL12 & Rho & & & & 0.348 & 0.541 \\
& $p$-Value & & & & 0.009 & $<0.001$ \\
CXCL13 & Rho & & & & & 0.544 \\
& $p$-Value & & & & & $<0.001$ \\
\hline
\end{tabular}

CD: Cluster of differentiation; CXCL: C-X-C motif chemokine ligand.

cells are important for the induction of antitumor immunity by priming naïve T-cells and leading them to activate and differentiate into effector cells (21). Chemokines, including CCL3, CCL4, CCR5L, CCL17, and CCR4 (which are responsible for recruiting naïve cytotoxic T-lymphocytes) are secreted by DCs. In the present study, we demonstrated that CD11c positivity was significantly correlated with $\mathrm{CD}^{+}$and $\mathrm{CD}^{+}$T-cells counts and TIL levels in surgical specimens of patients with TNBC. In addition, we analyzed the distribution of immunohistochemical CD11c expression and found that CD $11 \mathrm{c}^{+}$cells were located in areas with high numbers of TILs. Therefore, we confirm there to be a close association between CD11c ${ }^{+}$DCs and T-cells in TNBC.

We also identified a positive correlation between CD11c positivity and the presence of TLSs in the TNBC microenvironment. The positive relationship of $C D 11 C$ expression with $C D 4, C D 8$, and genes related to TLSs was also confirmed in gene-expression analysis using NanoStringbased gene expression data and TCGA breast cancer RNA sequencing data. In the chronic inflammatory environment (including in the context of tumor growth), lymphoid neogenesis is induced, and TLSs structurally and functionally resembling secondary lymphoid organs are formed (22). BCell zones with germinal centers and distinct T-cell-rich areas with DCs can be found in TLSs. We previously demonstrated that TLSs in breast cancer are usually present in areas surrounding invasive tumors and are closely associated with terminal duct lobular unit and ductal carcinoma in situ (2, 23, 24). Inflammatory cytokines and chemokines, such as LTa, LTa1b2, CXCL13, CCL21, CCL19, interleukin (IL)17, IL22, IL23, IL7, and IL27 produced by various cell types (including DCs and macrophages in the tumors) are involved in initiation, formation, and maintenance of TLSs (25). High endothelial venules and lymphatic vessels in TLSs enable 

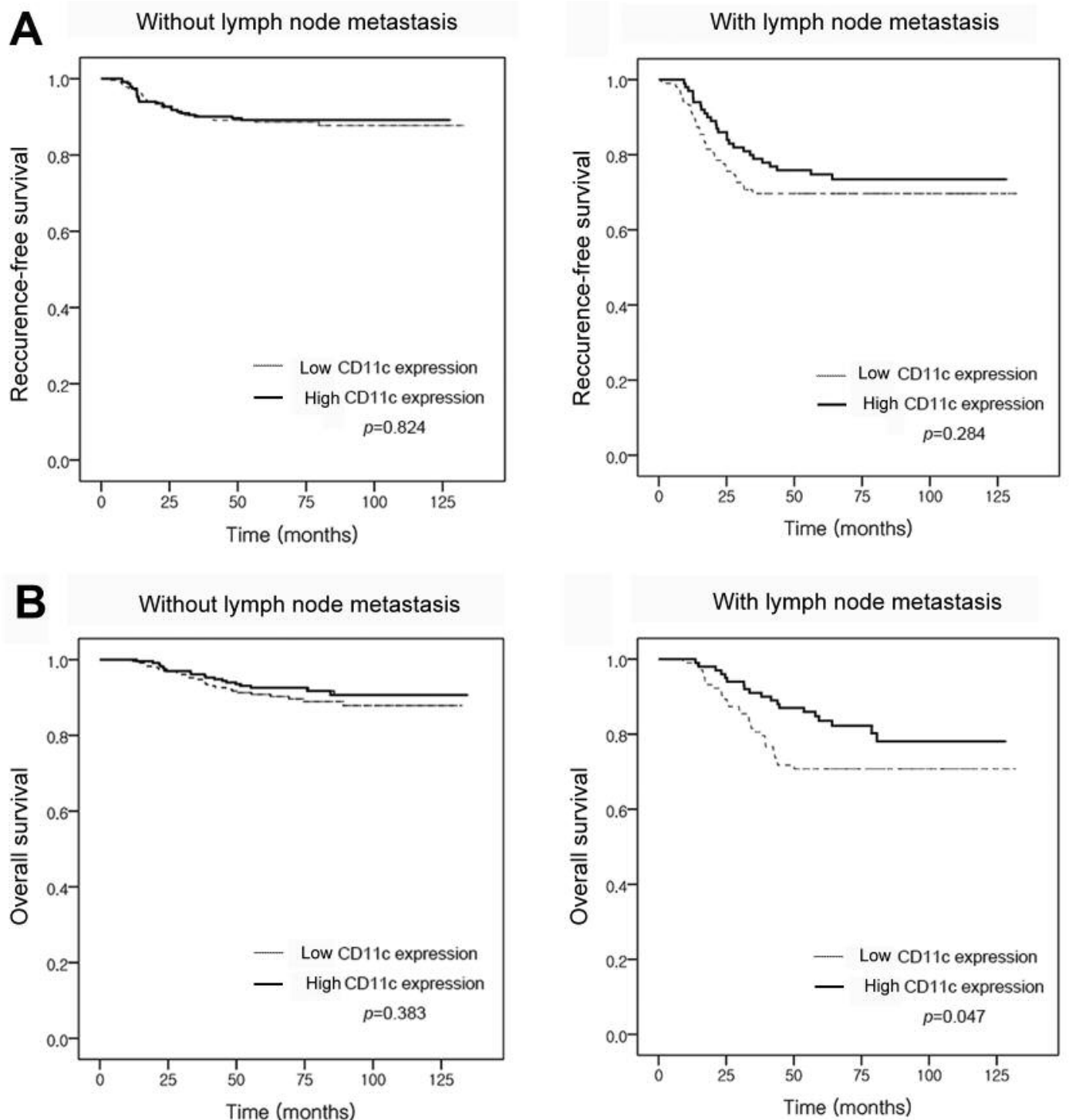

Figure 4. Kaplan-Meier survival analysis of recurrence-free (A) and overall (B) survival for patients with triple-negative breast cancer according to cluster of differentiation (CD)11c expression and lymph node status. In patients without lymph node metastasis, no difference recurrence-free or overall survival according to CD11c expression was observed (left panel). On the other hand, high expression of CD11c was related to better overall survival in patients with lymph node metastasis (right panel).

recruitment of peripheral immune cells into the tumor microenvironment, and accordingly activated immune cells generate local antitumor immunity. Thus, the presence and abundance of TLSs in the tumor are associated with the number of TILs and beneficial clinical outcomes. We previously reported that TLSs are abundant in TNBC and that the abundance of TLSs is associated with the TIL level (2). Patients with moderate or abundant TLSs had better survival than those with few or no TLSs at higher pathological stage regarding tumor, lymph node, and distant metastasis. Moreover, the presence of TLSs at a site of breast cancer metastasis exhibited was significantly correlated with the abundance of TILs in metastatic sites and better overall survival (unpublished data).

We showed that, in the context of lymph node metastasis, patients with high CD11c expression had a better overall survival. However, in multivariate analysis, CD11c expression was not an independent prognostic factor for better overall survival. This result might be caused by the strong association between CD11c positivity and TIL level, which is a significantly important prognostic factor in TNBC. 
Table III. Correlation between genes associated with T-cells and tertiary lymphoid structures and CD11C from patients with triple-negative breast cancer [The Cancer Genome Atlas data $(n=189)]$.

\begin{tabular}{|c|c|c|c|c|c|c|c|c|}
\hline & & $C D 8 A$ & $C D 8 B$ & CCL21 & CXCL12 & CXCL13 & $L T B$ & $C D 11 C$ \\
\hline \multirow[t]{2}{*}{$C D 4$} & Rho & 0.705 & 0.554 & 0.415 & 0.395 & 0.691 & 0.689 & 0.867 \\
\hline & $p$-Value & 0.001 & $<0.001$ & $<0.001$ & $<0.001$ & $<0.001$ & $<0.001$ & $<0.001$ \\
\hline \multirow[t]{2}{*}{$C D 8 A$} & Rho & & 0.791 & 0.416 & 0.263 & 0.787 & 0.630 & 0.573 \\
\hline & $p$-Value & & $<0.001$ & $<0.001$ & $<0.001$ & $<0.001$ & $<0.001$ & $<0.001$ \\
\hline \multirow[t]{2}{*}{$C D 8 B$} & Rho & & & 0.372 & 0.152 & 0.630 & 0.503 & 0.445 \\
\hline & $p$-Value & & & $<0.001$ & 0.037 & $<0.001$ & $<0.001$ & $<0.001$ \\
\hline \multirow[t]{2}{*}{ CCL21 } & Rho & & & & 0.467 & 0.400 & 0.573 & 0.443 \\
\hline & $p$-Value & & & & $<0.001$ & $<0.001$ & $<0.001$ & $<0.001$ \\
\hline \multirow[t]{2}{*}{ CXCL12 } & Rho & & & & & 0.174 & 0.244 & 0.409 \\
\hline & $p$-Value & & & & & 0.016 & $<0.001$ & $<0.001$ \\
\hline \multirow[t]{2}{*}{ CXCL13 } & Rho & & & & & & 0.642 & 0.560 \\
\hline & $p$-Value & & & & & & $<0.001$ & $<0.001$ \\
\hline \multirow[t]{2}{*}{$L T B$} & Rho & & & & & & & 0.643 \\
\hline & $p$-Value & & & & & & & $<0.001$ \\
\hline
\end{tabular}

CD: Cluster of differentiation; CXCL: C-X-C motif chemokine ligand; LTB: lymphotoxin beta.

CD11c can also be expressed by activated macrophages, natural killer cells, and T-cells (26-29). Better clinical outcomes in colorectal cancer, gastric cancer, and malignant melanoma have been associated with CD208 (dendritic cell-lysosomalassociated membrane glycoprotein, DC-LAMP) expressed on mature DCs located in T-cell areas of lymphoid tissues, as well as CD86 (B7.2, a ligand of CD28/CTLA-4) expressing mature DCs (30-32). Another study showed that tumor-infiltrating $\mathrm{CD}_{1} \mathrm{a}^{+}$immature DCs were associated with an unfavorable prognosis in colorectal cancer (33). It is possible that opposing actions of antigen-presenting cells can be exerted on tumor progression, depending on the polarization and activation status of DCs or macrophages. The DC phenotype can also be switched from immunoenhancing to immunosuppressive by factors secreted in the tumor microenvironment (34). Immunosuppressive DCs are associated with low expression of co-stimulatory molecules, blunting antigen presentation, and up-regulation of regulatory molecules such as programmed death 1 within tumors. Thus, further studies elucidating subsets and characteristics of antigen-presenting cells using different markers together with CD11c are warranted.

In conclusion, this study demonstrated a close correlation of CD11c expression with TILs and TLSs in TNBC. Therapeutic modalities enhancing the number and activation of DCs in the tumor microenvironment could facilitate infiltration of TILs and yield better clinical outcomes.

\section{Acknowledgements}

This study was supported by Basic Science Research Programs, through the National Research Foundation of Korea (NRF), funded by the Ministry of Science, ICT \& Future Planning, Republic of Korea (2017R1D1A1B03035491 and 2017R1D1A1B03033104).

\section{Conflicts of Interest}

The Authors declare no conflicts of interest in regard to this study.

\section{References}

1 Wein L, Savas P, Luen SJ, Virassamy B, Salgado R and Loi S: Clinical validity and utility of tumor-infiltrating lymphocytes in routine clinical practice for breast cancer patients: current and future directions. Front Oncol 7: 156, 2017.

2 Lee HJ, Park IA, Song IH, Shin SJ, Kim JY, Yu JH and Gong G: Tertiary lymphoid structures: prognostic significance and relationship with tumour-infiltrating lymphocytes in triplenegative breast cancer. J Clin Pathol 69: 422-430, 2016.

3 Park IA, Heo SH, Song IH, Kim YA, Park HS, Bang WS, Park SY, Jo JH, Lee HJ and Gong G: Endoplasmic reticulum stress induces secretion of high-mobility group proteins and is associated with tumor-infiltrating lymphocytes in triple-negative breast cancer. Oncotarget 7: 59957-59964, 2016.

4 Lee HJ, Kim A, Song IH, Park IA, Yu JH, Ahn JH and Gong G: Cytoplasmic expression of high mobility group B1 (HMGB1) is associated with tumor-infiltrating lymphocytes (TILs) in breast cancer. Pathol Int 66: 202-209, 2016.

5 Hernandez C, Huebener P and Schwabe RF: Damage-associated molecular patterns in cancer: A double-edged sword. Oncogene 35: 5931-5941, 2016.

6 Liu Y, Yan W, Tohme S, Chen M, Fu Y, Tian D, Lotze M, Tang D and Tsung A: Hypoxia induced HMGB1 and mitochondrial DNA interactions mediate tumor growth in hepatocellular carcinoma through Toll-like receptor 9. J Hepatol 63: 114-121, 2015.

7 Apetoh L, Ghiringhelli F, Tesniere A, Obeid M, Ortiz C, Criollo A, Mignot G, Maiuri MC, Ullrich E, Saulnier P, Yang H, Amigorena S, Ryffel B, Barrat FJ, Saftig P, Levi F, Lidereau R, Nogues C, Mira JP, Chompret A, Joulin V, Clavel-Chapelon F, Bourhis J, Andre F, Delaloge S, Tursz T, Kroemer G and 
Zitvogel L: Toll-like receptor 4-dependent contribution of the immune system to anticancer chemotherapy and radiotherapy. Nat Med 13: 1050-1059, 2007.

8 Tesniere A, Panaretakis T, Kepp O, Apetoh L, Ghiringhelli F, Zitvogel L and Kroemer G: Molecular characteristics of immunogenic cancer cell death. Cell Death Differ 15: 3-12, 2008.

9 Murakami T, Homma Y, Matsuyama R, Mori R, Miyake K, Tanaka Y, Den K, Nagashima Y, Nakazawa M, Hiroshima Y, Ueda M, Tanaka K, Hoffman RM and Bouvet M: Neoadjuvant chemoradiotherapy of pancreatic cancer induces a favorable immunogenic tumor microenvironment associated with increased major histocompatibility complex class I-related chain A/B expression. J Surg Oncol 116: 416-426, 2017.

10 Peng RQ, Wu XJ, Ding Y, Li CY, Yu XJ, Zhang X, Pan ZZ, Wan DS, Zheng LM, Zeng YX and Zhang XS: Co-expression of nuclear and cytoplasmic HMGB1 is inversely associated with infiltration of $\mathrm{CD}_{45 \mathrm{RO}^{+}} \mathrm{T}$-cells and prognosis in patients with stage IIIB colon cancer. BMC Cancer 10: 496, 2010.

11 Aguilar-Cazares D, Meneses-Flores M, Prado-Garcia H, IslasVazquez L, Rojo-Leon V, Romero-Garcia S, Rivera-Rosales RM and Lopez-Gonzalez JS: Relationship of dendritic cell density, HMGB 1 expression, and tumor-infiltrating lymphocytes in nonsmall cell lung carcinomas. Appl Immunohistochem Mol Morphol 22: 105-113, 2014.

12 Park IA, Hwang SH, Song IH, Heo SH, Kim YA, Bang WS Park HS, Lee M, Gong G and Lee HJ: Expression of the MHC class II in triple-negative breast cancer is associated with tumorinfiltrating lymphocytes and interferon signaling. PLoS One 12: e0182786, 2017.

13 Elston CW and Ellis IO: Pathological prognostic factors in breast cancer. I. The value of histological grade in breast cancer: experience from a large study with long-term follow-up. Histopathology 19: 403-410, 1991.

14 Hendry S, Salgado R, Gevaert T, Russell PA, John T, Thapa B, Christie M, van de Vijver K, Estrada MV, Gonzalez-Ericsson PI, Sanders M, Solomon B, Solinas C, Van den Eynden G, Allory Y, Preusser M, Hainfellner J, Pruneri G, Vingiani A, Demaria S, Symmans F, Nuciforo P, Comerma L, Thompson EA, Lakhani S, Kim SR, Schnitt S, Colpaert C, Sotiriou C, Scherer SJ, Ignatiadis M, Badve S, Pierce RH, Viale G, Sirtaine N, PenaultLlorca F, Sugie T, Fineberg S, Paik S, Srinivasan A, Richardson A, Wang Y, Chmielik E, Brock J, Johnson DB, Balko J, Wienert S, Bossuyt V, Michiels S, Ternes N, Burchardi N, Luen SJ, Savas P, Klauschen F, Watson PH, Nelson BH, Criscitiello C, O'Toole S, Larsimont D, de Wind R, Curigliano G, Andre F, Lacroix-Triki M, van de Vijver M, Rojo F, Floris G, Bedri S Sparano J, Rimm D, Nielsen T, Kos Z, Hewitt S, Singh B, Farshid G, Loibl S, Allison KH, Tung N, Adams S, WillardGallo K, Horlings HM, Gandhi L, Moreira A, Hirsch F, Dieci MV, Urbanowicz M, Brcic I, Korski K, Gaire F, Koeppen H, Lo A, Giltnane J, Rebelatto MC, Steele KE, Zha J, Emancipator K, Juco JW, Denkert C, Reis-Filho J, Loi S and Fox SB: Assessing Tumor-infiltrating Lymphocytes in Solid Tumors: A Practical Review for Pathologists and Proposal for a Standardized Method From the International Immunooncology Biomarkers Working Group: Part 1: Assessing the host immune response, TILs in invasive breast carcinoma and ductal carcinoma in situ, metastatic tumor deposits and areas for further research. Adv Anat Pathol 24: 235-251, 2017.
15 Lee HJ, Lee JJ, Song IH, Park IA, Kang J, Yu JH, Ahn JH and Gong G: Prognostic and predictive value of NanoString-based immune-related gene signatures in a neoadjuvant setting of triple-negative breast cancer: relationship to tumor-infiltrating lymphocytes. Breast Cancer Res Treat 151: 619-627, 2015.

16 Geiss GK, Bumgarner RE, Birditt B, Dahl T, Dowidar N, Dunaway DL, Fell HP, Ferree S, George RD, Grogan T, James JJ, Maysuria M, Mitton JD, Oliveri P, Osborn JL, Peng T, Ratcliffe AL, Webster PJ, Davidson EH, Hood L and Dimitrov $\mathrm{K}$ : Direct multiplexed measurement of gene expression with color-coded probe pairs. Nat Biotechnol 26: 317-325, 2008.

17 Gao J, Aksoy BA, Dogrusoz U, Dresdner G, Gross B, Sumer SO, Sun Y, Jacobsen A, Sinha R, Larsson E, Cerami E, Sander C and Schultz N: Integrative analysis of complex cancer genomics and clinical profiles using the cBioPortal. Sci Signal 6: pl1, 2013.

18 Cao X, Liu M, Wang P and Liu DY: Intestinal dendritic cells change in number in fulminant hepatic failure. World $\mathbf{J}$ Gastroenterol 21: 4883-4893, 2015.

19 Song IH, Heo SH, Bang WS, Park HS, Park IA, Kim YA, Park SY, Roh J, Gong G and Lee HJ: Predictive value of tertiary lymphoid structures assessed by high endothelial venule counts in the neoadjuvant setting of triple-negative breast cancer.. Cancer Res Treat 49: 399-407, 2017.

20 Wang Y, Xu B, Hu WW, Chen LJ, Wu CP, Lu BF, Shen YP and Jiang JT: High expression of CD11c indicates favorable prognosis in patients with gastric cancer. World J Gastroenterol 21: 9403-9412, 2015.

21 Thaiss CA, Semmling V, Franken L, Wagner H and Kurts C: Chemokines: A new dendritic cell signal for $\mathrm{T}$ cell activation. Front Immunol 2: 31, 2011

22 Dieu-Nosjean MC, Goc J, Giraldo NA, Sautes-Fridman C and Fridman WH: Tertiary lymphoid structures in cancer and beyond. Trends Immunol 35: 571-580, 2014.

23 Lee HJ, Kim JY, Park IA, Song IH, Yu JH, Ahn JH and Gong G: Prognostic significance of tumor-infiltrating lymphocytes and the tertiary lymphoid structures in HER2-positive breast cancer treated with adjuvant trastuzumab. Am J Clin Pathol 144: 278288, 2015.

24 Kim A, Heo SH, Kim YA, Gong $G$ and Jin Lee H: An Examination of the Local Cellular immune response to examples of both ductal carcinoma in situ (DCIS) of the breast and DCIS with microinvasion, with emphasis on tertiary lymphoid structures and tumor infiltrating lymphoctytes. Am J Clin Pathol 146: 137-144, 2016

25 Jing F and Choi EY: Potential of cells and cytokines/chemokines to regulate tertiary lymphoid structures in human diseases. Immune Netw 16: 271-280, 2016.

26 Beyer M, Wang H, Peters N, Doths S, Koerner-Rettberg C, Openshaw PJ and Schwarze J: The beta2 integrin CD11c distinguishes a subset of cytotoxic pulmonary $\mathrm{T}$ cells with potent antiviral effects in vitro and in vivo. Respir Res 6: 70, 2005.

27 Cooney LA, Gupta M, Thomas S, Mikolajczak S, Choi KY, Gibson C, Jang IK, Danziger S, Aitchison J, Gardner MJ, Kappe SH and Wang R: Short-lived effector CD8 T cells induced by genetically attenuated malaria parasite vaccination express CD11c. Infect Immun 81: 4171-4181, 2013.

28 Aranami T, Miyake S and Yamamura T: Differential expression of CD11c by peripheral blood NK cells reflects temporal activity of multiple sclerosis. J Immunol 177: 5659-5667, 2006. 
29 Misharin AV, Morales-Nebreda L, Mutlu GM, Budinger GR and Perlman H: Flow cytometric analysis of macrophages and dendritic cell subsets in the mouse lung. Am J Respir Cell Mol Biol 49: 503-510, 2013.

30 Gulubova MV, Ananiev JR, Vlaykova TI, Yovchev Y, Tsoneva $\mathrm{V}$ and Manolova IM: Role of dendritic cells in progression and clinical outcome of colon cancer. Int J Colorectal Dis 27: 159$169,2012$.

31 Ishigami S, Ueno S, Matsumoto M, Okumura H, Arigami T, Uchikado Y, Setoyama T, Arima H, Sasaki K, Kitazono M, Shinchi H, Kijima $\mathrm{Y}$ and Natsugoe S: Prognostic value of CD208-positive cell infiltration in gastric cancer. Cancer Immunol Immunother 59: 389-395, 2010.

32 Ladanyi A, Kiss J, Somlai B, Gilde K, Fejos Z, Mohos A, Gaudi I and Timar J: Density of DC-LAMP(+) mature dendritic cells in combination with activated T-lymphocytes infiltrating primary cutaneous melanoma is a strong independent prognostic factor. Cancer Immunol Immunother 56: 1459-1469, 2007.
33 Sandel MH, Dadabayev AR, Menon AG, Morreau H, Melief CJ, Offringa R, van der Burg SH, Janssen-van Rhijn CM, Ensink NG, Tollenaar RA, van de Velde CJ and Kuppen PJ: Prognostic value of tumor-infiltrating dendritic cells in colorectal cancer: Role of maturation status and intratumoral localization. Clin Cancer Res 11: 2576-2582, 2005.

34 Tran Janco JM, Lamichhane P, Karyampudi L and Knutson KL: Tumor-infiltrating dendritic cells in cancer pathogenesis. J Immunol 194: 2985-2991, 2015.
Received July 24, 2018

Revised September 14, 2018 Accepted September 19, 2018 